\title{
Aldose reductase inhibition, nerve perfusion, oxygenation and function in streptozotocin-diabetic rats: dose-response considerations and independence from a myo-inositol mechanism
}

\author{
N. E. Cameron ${ }^{1}$, M. A. Cotter ${ }^{1}$, K.C. Dines ${ }^{1}$, E. K.Maxfield ${ }^{1}$, F. Carey ${ }^{2}$, D.J. Mirrlees ${ }^{2}$ \\ ${ }^{1}$ Department of Biomedical Sciences, University of Aberdeen, Scotland, UK \\ ${ }^{2}$ ZENECA Pharmaceuticals, Macclesfield, Cheshire, England, UK
}

\begin{abstract}
Summary We examined the effects of aldose reductase inhibition on nerve biochemistry and function, blood flow and endoneurial oxygenation in experimental diabetes mellitus. After 1 month untreated diabetes in rats, treatment with the novel sulphonylnitromethane aldose reductase inhibitor, ZENECA ZD5522, prevented a progressive increase in sciatic nerve resistance to hypoxic conduction failure $(p<0.05)$. Motor conduction velocity deficits after 4 months untreated diabetes were rapidly returned to normal within 12 days $(p<0.0001)$ by ZD5522 treatment. Following 2-months untreated diabetes, examination of 1 month ZD5522 treatment dose-response relationships for correction of nerve sorbitol and fructose accumulations and reduction in myo-inositol concentration, sciatic motor and saphenous sensory conduction velocity and sciatic blood flow by laser-Doppler flowmetry revealed poor agreement between nerve function and biochemical indices. In addition, polyol accumulation differed between sciatic and saphenous nerves, the latter showing ten-fold lower sorbitol concentrations. Laser-Doppler blood flow was $60 \%$ decreased by untreated diabetes $(p<0.001)$ and there was a strong correlation
\end{abstract}

between ZD5522-mediated increases in blood flow and conduction velocity $(p<0.0001)$. Measurement of nutritive endoneurial blood flow by microelectrode polarography and hydrogen clearance showed $44 \%$ and $45 \%$ deficits for 1 and 2 months untreated diabetes $(p<0.001)$ that were prevented by ponalrestat and ZD5522 treatments, respectively. In contrast, 2 months myo-inositol treatment from diabetes induction did not prevent reduction in blood flow or sciatic motor conduction velocity. A $37 \%$ reduction in endoneurial oxygen tension after 2 months diabetes $(p<0.001)$ was completely prevented by ZD5522 treatment $(p<$ 0.001 ). The data show that a very high degree of polyol pathway blockade is necessary to correct nerve functional deficits and that aldose reductase inhibitors have a neurovascular action that does not depend on restoration of nerve myo-inositol. [Diabetologia (1994) 37 : 651-663]

Key words Neuropathy, nerve conduction, hypoxia, ischaemia, nerve blood flow, endoneurial oxygen tension, polyol pathway, aldose reductase, myo-inositol, streptozotocin, diabetic rat.
Received: 27 October 1993 and in revised form: 8 January 1994

Corresponding author: Professor N. E. Cameron, Department of Biomedical Sciences, University of Aberdeen, Marischal College, Aberdeen AB9 1 AS, Scotland, UK

Abbreviations: ARI, aldose reductase inhibitor; $\mathrm{ED}_{50}, 50 \%$ effective dose; EMG, electromyogram; $\mathrm{Na}^{+}-\mathrm{K}^{+}$-ATPase, sodium potassium adenosine triphosphatase; $\mathrm{NCV}$, nerve conduction velocity; NO, nitric oxide; $\mathrm{RHCF}$, resistance to hypoxic conduction failure.
Treatment with ARIs can prevent the development of NCV abnormalities in experimental models of diabetes mellitus [1,2]. However, their effectiveness in reversing existing abnormalities has been questioned [3], as has long-term efficacy [4]. Results of clinical trials have shown at best only modest improvements in objective measures of function such as NCV [5], although morphometric analysis of sural nerve biopsies has shown an increased number of regenerating fibres [6].

Where efficacy is debated, attention must focus on the dose-response relationship for a treatment. Thus, animal studies of ARI effects on NCV generally em- 
ploy doses at least one order of magnitude greater than those used in clinical studies. A recent study showed that a dose of the ARI, ponalrestat, similar to that used in clinical trials which failed to find beneficial effects [7], was also completely ineffective on $\mathrm{NCV}$ in diabetic rats [8]. Detailed data relating nerve function to treatment dose and their relation to biochemical indicators of polyol pathway activity are lacking in the literature. Thus, one aim of this study was to examine this point.

The mechanisms of ARI-mediated correction of nerve dysfunction are not known in detail. A neurochemical hypothesis linking polyol pathway flux, myoinositol and phosphoinositide metabolism, $\mathrm{Na}^{+}-\mathrm{K}^{+}$ATPase activity and NCV [9] has not been substantiated by several studies $[2,10,11]$. However, a vascular hypothesis, attributing functional abnormalities to reduced nerve blood flow and endoneurial hypoxia [12], can account for the beneficial effects of treatments which do not alter polyol pathway activity, such as vasodilators, essential fatty acids, aminoguanidine and chronic electrical stimulation [2,13,14]. Several studies have recently shown that ARIs prevent deficits in endothelium-dependent relaxation caused by diabetes or acute hyperglycaemia [15-17]. Thus, ARIs could act through a vascular rather than a neurochemical mechanism. This hypothesis was tested by examining ARI effects on sciatic nerve blood flow, the nutritive component of endoneurial flow, and the consequences for endoneurial oxygen tension. Because of a postulated connection between polyol pathway and myo-inositol metabolism [9] and evidence of hyperglycaemia and myoinositol linked changes in conducting vessels [16], the effects of myo-inositol treatment on endoneurial blood flow were also examined.

\section{Materials and methods}

\section{Animals and diabetes induction}

Male Sprague-Dawley rats (Aberdeen University breeding colony), 19 weeks old at the start of the study were used. Nondiabetic animals acted as onset controls. Others were given streptozotocin (Sigma, Poole, Dorset, UK) at $40-45 \mathrm{mg} \cdot \mathrm{kg}^{-1}$ in $20 \mathrm{mmol} \cdot 1^{-1}$ sodium citrate buffer, $\mathrm{pH}$ 4.5, i.p. . Diabetes was verified $24 \mathrm{~h}$ later by estimating hyperglycaemia and glycosuria (Visidex II and Diastix; Ames, Slough, UK). Diabetic rats were tested weekly, and weighed daily. They were rejected if blood glucose concentration was less than $20 \mathrm{mmol} \cdot \mathrm{l}^{-1}$ or if they showed a consistent increase in body weight over 3 days. Samples for plasma glucose measurement using a standard test kit (GOD-Perid method; Boehringer Mannheim, Mannheim, FRG) were taken from the tail vein or carotid artery on the day of final experiments.

Diabetic rats were used in four studies, along with nondiabetic controls. The first study concerned the effect of ARI treatment on RHCF. Groups employed were 1 and 2 month diabetic controls, and a reversal group treated with a novel sulphonylnitromethane ARI [18], 3', 5'-dimethyl-4'-nitromethylsulphonyl-2-(2-tolyl)acetanilide (ZD5522; ZENECA Pharma- ceuticals, Macclesfield, Cheshire, UK) in the drinking water at a dose of approximately $5 \mathrm{mg} \cdot \mathrm{kg}^{-1}$. day ${ }^{-1}$ for 1 month, following 1 month of untreated diabetes. The second study examined the time course of reversal of $\mathrm{NCV}$ reductions by ARI treatment using serial measurement of NCV in motor nerve fibres supplying tibialis anterior muscle after 4 months untreated diabetes. Treatment with ARI was in the drinking water at a dose of approximately $5 \mathrm{mg} \cdot \mathrm{kg}^{-1} \cdot \mathrm{day}^{-1}$. The third study examined the dose-response relations for reversal of NCV deficits with 1 month treatment following 2 months untreated diabetes. The ARI was given daily by gavage in six groups at doses of $0.25,0.5$, $1.0,2.0,4.0$ or $8.0 \mathrm{mg} \cdot \mathrm{kg}^{-1}$. The fourth study employed a dose of $8.0 \mathrm{mg} \cdot \mathrm{kg}^{-1} \cdot \mathrm{day}^{-1}$ in the drinking water, given over a 2 -month period from induction of diabetes, to investigate endoneurial blood flow and oxygen tension. Control rats were also treated with ARI to examine any effects on blood flow. An additional group, treated from induction of diabetes for 1 month with the ARI, ponalrestat, (ZENECA Pharmaceuticals) at a dose of $100 \mathrm{mg} \cdot \mathrm{kg}^{-1} \cdot \mathrm{day}^{-1}$ by gavage, was also used to study the effects of a structurally unrelated ARI on the nutritive component of sciatic endoneurial blood flow. A further group was treated for 2 months from diabetes induction with myo-inositol (Sigma) in the drinking water such that each rat received a daily dose of approximately $1 \mathrm{~g}$. This is equivalent to a $2.5 \%$ dietary supplement. Measurements were made of sciatic motor NCV to tibialis anterior muscle and, in the contralateral nerve, endoneurial blood flow.

\section{Investigation 1: in vitro measurement of sciatic nerve resistance to hypoxic conduction failure}

The sciatic nerve trunk, between the sciatic notch and the knee, was removed under urethane anaesthesia $\left(1-1.5 \mathrm{mg} \cdot \mathrm{kg}^{-1}\right)$ to a tissue bath filled with Krebs solution gassed with $95 \% \mathrm{O}_{2}: 5 \%$ $\mathrm{CO}_{2}(\mathrm{pH} 7.35)$ at $35^{\circ} \mathrm{C}$. The Krebs solution contained $40 \mathrm{mmol} \cdot \mathrm{l}^{-1}$ glucose for nerves from diabetic rats, and $5.5 \mathrm{mmol} \cdot \mathrm{l}^{-1}$ for nerves from non-diabetic rats. They were left to equilibrate for approximately $30 \mathrm{~min}$, then the chamber was refilled with liquid paraffin pre-gassed with $100 \% \mathrm{~N}_{2}$ for $1 \mathrm{~h}$ and $\mathrm{N}_{2}$ gassing continued. Myelinated fibres in nerves were stimulated with just supramaximal pulses $(1 \mathrm{~Hz}, 0.05 \mathrm{~ms}$ width, $10 \mathrm{~mA})$ and compound action potential amplitude was monitored at 2-min intervals until it fell below $10 \%$ of its initial value.

\section{Investigation 2: serial measurements of sciatic peroneal nerve conduction velocity}

A group of seven diabetic rats was used to investigate changes in NCV to tibialis anterior muscle as previously described [14], over a 14-day ARI treatment period following 4 months untreated diabetes. Under halothane anaesthesia ( $2-5 \%$ in air), sterile bipolar needle-stimulating electrodes ( $2 \mathrm{~mm}$ separation of tips) were inserted through the skin to stimulate the sciatic nerve at the sciatic notch and popliteal fossa. A sterile concentric bipolar recording electrode was inserted into tibialis anterior muscle. Leg skin temperature was monitored by a thermistor probe and kept in the range $36-38^{\circ} \mathrm{C}$ by radiant heat. EMGs evoked from both stimulation sites were averaged eight times and latencies of the first inflections were measured. The sciatic nerve between the two stimulating electrodes takes a fairly straight course, and interelectrode distances were used to calculate conduction velocity. NCV values obtained by this serial method are in good agreement with those found in acute measurements [3]. 


\section{Investigations 1, 3 and 4: acute measurement of nerve conduction velocity}

In final experiments, rats were anaesthetized with urethane (investigation $1,1.0-1.5 \mathrm{~g} \cdot \mathrm{kg}^{-1}$ i.p.) or inactin $\left(50-100 \mathrm{mg} \cdot \mathrm{kg}^{-1}\right.$ i.p.). Methods have been described in detail previously [3, 14]. Briefly, the sciatic nerve was exposed and bipolar stimulating electrodes were placed close to it at the sciatic notch and the knee. A concentric bipolar electrode was inserted into either tibialis anterior (peroneal sciatic division) or gastrocnemius (tibial sciatic division) muscles to monitor evoked EMG activity. Potentials from each stimulating site were averaged eight times. NCVs for tibialis anterior and gastrocnemius were calculated by dividing the distance between stimulating electrodes by the average latency difference between the onset of EMG potentials evoked from the two sites. The results of the two motor nerve measurements were averaged and taken to be representative of sciatic motor NCV [19]. Nerve temperature was monitored using a thermocouple probe, and maintained in the range $36.5-37.5^{\circ} \mathrm{C}$ by radiant heat. Body temperature was also maintained around $37^{\circ} \mathrm{C}$ using radiant heat and monitored by a rectal probe. Sensory NCVs were also measured between groin and ankle for the saphenous nerve.

\section{Investigation 3: laser-Doppler measurement of nerve blood flow}

After measurement of NCV, the trachea was cannulated for artificial ventilation and a carotid cannula was used to monitor mean systemic blood pressure. Core temperature of the animal was monitored and regulated between 37 and $38^{\circ} \mathrm{C}$, using a rectal probe and radiant heat. Whole nerve blood flow was estimated using a laser-Doppler instrument $\left(\mathrm{BPM}^{2}\right.$ Laserflo; Vincent Medical, Slough, Bucks., UK) with a $0.8 \mathrm{~mm}$ diameter probe [14]. This was applied under microscope control to an area of the sciatic trunk as free as possible from large epi/perineurial vessels, care being taken not to compress the nerve. The exposed nerve was then covered with liquid paraffin to avoid tissue dehydration. Laser-Doppler flow values (arbitrary units) were allowed to reach a stable baseline over $15 \mathrm{~min}$ before readings were taken, averaged over a further 10-min period. Vascular conductance (arbitrary units) was calculated by dividing blood flow by mean systemic blood pressure.

\section{Investigation 3: sciatic nerve polyol pathway metabolite and myo-inositol levels}

Sciatic and saphenous nerve samples were taken from the contralateral leg before animals were killed by exsanguination. They were frozen in liquid $\mathrm{N}_{2}$ and stored at $-80^{\circ} \mathrm{C}$ until subsequent analysis. Nerve sugars and polyols were determined by gas chromatography of trimethylsilyl derivatives prepared from aqueous deproteinized extracts [20].

\section{Investigation 4: endoneurial blood flow and oxygen tension measured by microelectrode polarography}

Rats were anaesthetized with inactin (50-100 $\mathrm{mg} \mathrm{kg}^{-1} \mathrm{i} . \mathrm{p}$.) and were prepared as for laser-Doppler recording. The skin around the sciatic nerve incision was sutured to a metal ring and used to form a pool which was filled with liquid paraffin at $37^{\circ} \mathrm{C}$ to a depth of at least $1 \mathrm{~cm}$ to minimise diffusion of gasses directly to or from the nerve. Rats were given neuromuscular blockade using $d$-tubocurarine (Sigma, $2.0 \mathrm{mg} \mathrm{kg}^{-1}$ via the carotid cannula) and artificially ventilated. The level of anaesthesia was monitored by observing any reaction of blood pressure to manipulation, and supplementary inactin was given as necessary. Nerve blood flow was measured by microelectrode hydrogen polarography as previously described $[12,19]$. Briefly, a glass-insulated platinum microelectrode (tip diameter $2.0-8.0 \mu \mathrm{m}$ ) was inserted into the middle portion of the sciatic nerve, above its trifurcation, and polarized at $0.25 \mathrm{~V}$ with respect to a reference electrode inserted subcutaneously in the flank of the rat. $10 \% \mathrm{H}_{2}$ was added to the inspired gas, the proportions of $\mathrm{O}_{2}$ and $\mathrm{N}_{2}$ being adjusted to $20 \%$ and $70 \%$, respectively. When the $\mathrm{H}_{2}$ current recorded by the electrode had stabilized (20-40 min), indicating equilibrium with arterial blood, the $\mathrm{H}_{2}$ supply was shut off and $\mathrm{N}_{2}$ delivery was increased appropriately. The $\mathrm{H}_{2}$ clearance curve was recorded until baseline $(30 \mathrm{~min}$ to $1 \mathrm{~h})$. This procedure was then repeated at another nerve site. After the experiment, clearance curves were digitized and mono- or bi-exponential curves were fitted to the data by computer using appropriate software (Inplot; Graphpad, San Diego, Calif., USA). The slow exponent, representing nutritive flow [19], was accepted. The average of the two determinations was taken to represent sciatic endoneurial blood flow. Vascular conductance was calculated by dividing blood flow by mean arterial blood pressure during the recording period.

Endoneurial oxygen tensions were measured using methods similar to those described by Tuck et al. [12] and Newrick et al. [21] with glass-insulated platinum microelectrodes (tip diameter $<3.0 \mu \mathrm{m}$ ) which had been coated with a semipermeable membrane by dipping in collodion dissolved in xylene. Microelectrodes were polarised at $-0.75 \mathrm{~V}$ and response linearity was assessed in $\mathrm{NaCl}$ at $37^{\circ} \mathrm{C}$ bubbled with $\mathrm{O}_{2}-\mathrm{N}_{2}$ mixtures from $2 \%$ to $20 \% \mathrm{O}_{2}$. They were inserted approximately $100 \mu \mathrm{m}$ into the endoneurium and oxygen tension readings were taken at $50 \mu \mathrm{m}$ depth increments over a further $500 \mu \mathrm{m}$. For the occasionally encountered nerves that remained as separate tibial and peroneal branches over the course of the sciatic nerve, the larger tibial fascicle was used and the additional depth increment was restricted to $400 \mu \mathrm{m}$. This process was repeated at five different sites along the nerve, resulting in 45-55 tension measurements per nerve. The liquid paraffin pool surrounding the nerve was bubbled with $\mathrm{N}_{2}$ to reduce diffusion of atmospheric oxygen. Microelectrode responses were checked in $154 \mathrm{mmol} \cdot \mathrm{l}^{-1} \mathrm{NaCl}$ solution bubbled with air ( $21 \%$ oxygen) and in saturated sodium sulphite solution ( $0 \%$ oxygen) between penetrations. Results from a penetration were rejected if there was more than $10 \%$ sensitivity drift between successive calibrations. The rats were artificially ventilated with air, or with oxygen-enriched air if $\mathrm{PaO}_{2}$ fell below $80 \mathrm{~mm} \mathrm{Hg}$ and could not be corrected by adjusting respiratory parameters. $\mathrm{PaO}_{2}$ was measured after each penetration (Model $238 \mathrm{pH} /$ blood gas analyser; Ciba-Corning, Halstead, Essex, UK).

\section{Statistical analysis}

Data are expressed as mean \pm SEM. One-way analysis of variance was performed, followed by Bonferroni or Student-Newman-Keuls tests to assign differences to individual groups where overall significance $(p<0.05)$ was attained. Paired Student's $t$ tests were used to assess the significance of within-rat NCV changes in investigation 2, and unpaired tests were used for comparison with control levels. 
Table 1. Body weights, plasma glucose concentrations and sciatic motor and saphenous sensory conduction velocities for nondiabetic, diabetic and ZD5522-treated diabetic rats from Investigation 1

\begin{tabular}{|c|c|c|c|c|c|c|}
\hline \multirow[b]{2}{*}{ Group } & \multirow[b]{2}{*}{$n$} & \multicolumn{2}{|c|}{ Body weight (g) } & \multirow{2}{*}{$\begin{array}{l}\text { Plasma glucose } \\
\left(\mathrm{mmol} \cdot \mathrm{l}^{-1}\right)\end{array}$} & \multicolumn{2}{|c|}{ Conduction velocity $\left(\mathrm{m} \cdot \mathrm{s}^{-1}\right)$} \\
\hline & & Start & End & & motor & sensory \\
\hline$\overline{\text { Control }}$ & 10 & $467 \pm 9$ & & $10.6 \pm 1.2$ & $64.9 \pm 0.4$ & $59.7 \pm 0.8$ \\
\hline \multicolumn{7}{|l|}{ Diabetic } \\
\hline 1 month & 10 & $461 \pm 11$ & $357 \pm 13^{a}$ & $34.8 \pm 3.5^{\text {a }}$ & $51.0 \pm 0.4^{\mathrm{a}}$ & $51.6 \pm 0.8$ \\
\hline 2 month & 12 & $477 \pm 12$ & $359 \pm 13^{a}$ & $38.5 \pm 2.0^{\mathrm{a}}$ & $51.1 \pm 0.8^{\mathrm{a}}$ & $51.6 \pm 0.7^{\mathrm{a}}$ \\
\hline ZD5522-treated & 12 & $457 \pm 13$ & $383 \pm 15^{a}$ & $37.2 \pm 1.9^{\mathrm{a}}$ & $62.5 \pm 1.7^{\mathrm{b}}$ & $58.5 \pm 1.5^{b}$ \\
\hline
\end{tabular}

${ }^{a} p<0.001$ compared to control group;

${ }^{\mathrm{b}} p<0.001$, effect of ZD5522 treatment compared to 1 and

2 month diabetic groups

Data are mean \pm SEM

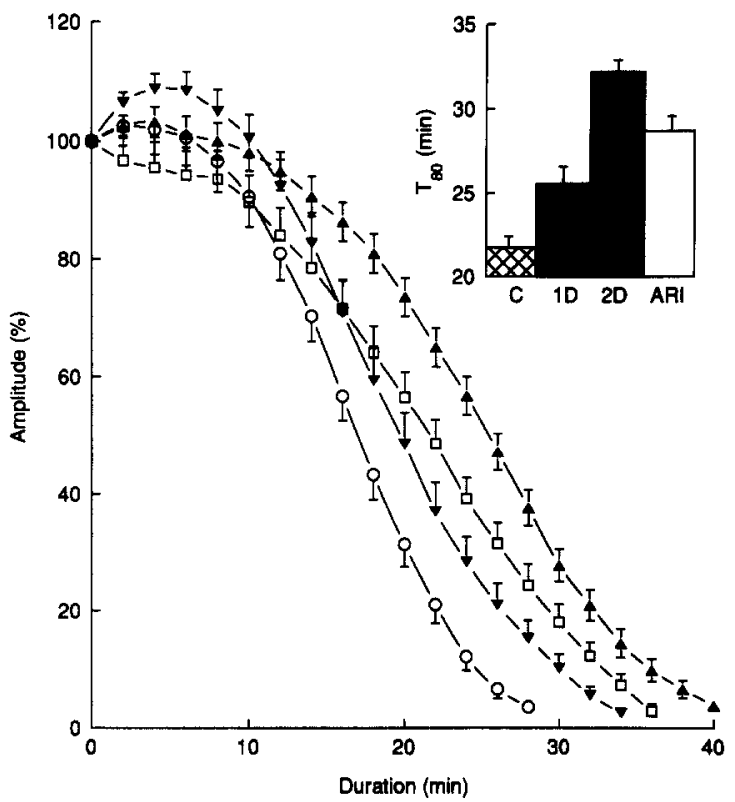

Fig. 1. Effects of ZD5522 treatment on sciatic nerve resistance to hypoxic conduction failure in vitro. Data are group means \pm SEM. Non-diabetic control group (O), $n=10 ; 1$-month diabetic group $(\boldsymbol{\nabla}), n=10$; 2 -month diabetic group $(\boldsymbol{\Delta}), n=12$; diabetic group treated with ZD5522 $\left(5 \mathrm{mg} \cdot \mathrm{kg}^{-1} \cdot \mathrm{day}^{-1}\right)$ for 1 month following 1 month untreated diabetes $(\square)$. Inset histogram, hypoxia times for an $80 \%$ reduction in sciatic compound action potential amplitude $\left(\mathrm{T}_{80}\right)$. C, non-diabetic control group; $1 \mathrm{D}, 1$-month diabetic, 2D, 2-month diabetic group; ARI, diabetic group treated with ZD5522 for 1 month following 1 month of untreated diabetes. Statistics: C vs $1 \mathrm{D}, p<0.05$; C vs $2 \mathrm{D}, p<0.001 ; 1 \mathrm{D}$ vs $2 \mathrm{D}, p<0.001$; C vs ARI, $p<0.001 ; 2 \mathrm{D}$ vs ARI, $p<0.05 ; 1 \mathrm{D}$ vs ARI, NS

\section{Results}

Investigation 1: effects of aldose reductase inhibition with $Z D 5522$ on sciatic nerve resistance to hypoxic conduction failure

Body weights were approximately $22 \%$ reduced by 1 and 2 months diabetes and all diabetic rats were hyperglycaemic (Table 1). These parameters were unaffected by ZD5522 treatment. Sciatic motor and sa- phenous sensory NCV (Table 1 ) were reduced by $21 \%$ and $14 \%$ after 1 month diabetes and this was maintained at 2 months. ZD5522 treatment during the second month of diabetes caused approximately $85 \%$ reversal of these conduction deficits.

The results of in vitro determination of RHCF are illustrated in Figure 1. Diabetes caused a progressive prolongation of the time taken for the sciatic compound action potential amplitude to decline when the preparation was exposed to hypoxia. ZD5522 treatment did not reverse the development of elevated hypoxic resistance that occurred over the first month of untreated diabetes; however, it limited further changes during the treatment period. The times for an $80 \%$ reduction in compound action potential amplitude $\left(\mathrm{T}_{80}\right)$ were $18 \%(p<0.05)$ and $49 \%(p<0.001)$ increased by 1 and 2 months diabetes, respectively. With ZD5522 treatment the $31 \%$ increase was not significantly different from the 1 month value but was less than for 2 month diabetes $(p<0.05)$.

\section{Investigation 2: time course of motor conduction velocity increases with ZD 5522 treatment}

Serial measurements of tibialis anterior motor NCV for the duration of reversal ZD5522 treatment following 4 months untreated diabetes are shown in Figure 2. There was a delayed increase in NCV after instigation of treatment, the first significant $(p<0.05)$ improvement of $7.7 \%$ over baseline being evident on day 7. By day $11, \mathrm{NCV}$ was not significantly different from the non-diabetic control value, but significantly greater than before treatment began $(p<0.0001)$.

\section{Investigation 3: nerve dose-response relationship for ZD5522 treatment}

Plasma glucose levels were elevated in all diabetic rats, and were not affected by ZD5522 treatment (Table 2). Glucose concentrations were higher than recorded for diabetic groups in investigation 1 , which are typical of 
Table 2. Body weight, plasma glucose concentration and systemic arterial blood pressures for rats from Investigation 3

\begin{tabular}{|c|c|c|c|c|c|}
\hline \multirow[b]{2}{*}{ Group } & \multirow[b]{2}{*}{$n$} & \multicolumn{2}{|c|}{ Body weight $(\mathrm{g})$} & \multirow{2}{*}{$\begin{array}{l}\text { Plasma glucose } \\
\left(\mathrm{mmol} \cdot \mathrm{l}^{-1}\right)\end{array}$} & \multirow{2}{*}{$\begin{array}{l}\text { Blood pressure } \\
(\mathrm{mmHg})\end{array}$} \\
\hline & & Start & End & & \\
\hline Control & 12 & $431 \pm 8$ & & $9.7 \pm 0.5$ & $123.5 \pm 6.4$ \\
\hline \multicolumn{6}{|l|}{ Diabetic } \\
\hline Untreated & 11 & $503 \pm 10$ & $325 \pm 10$ & $59.9 \pm 4.6$ & $113.7 \pm 5.3$ \\
\hline \multicolumn{6}{|c|}{ ZD5522-treated diabetic } \\
\hline $0.25 \mathrm{mg} \cdot \mathrm{kg}^{-1} \cdot \mathrm{day}^{-1}$ & 11 & $474 \pm 5$ & $349 \pm 8$ & $62.4 \pm 3.8$ & $122.9 \pm 5.2$ \\
\hline $0.5 \mathrm{mg} \cdot \mathrm{kg}^{-1} \cdot \mathrm{day}^{-1}$ & 14 & $501 \pm 7$ & $342 \pm 15$ & $60.2 \pm 3.2$ & $130.6 \pm 4.3$ \\
\hline $1.0 \mathrm{mg} \cdot \mathrm{kg}^{-1} \cdot \mathrm{day}^{-1}$ & 11 & $495 \pm 10$ & $326 \pm 11$ & $58.3 \pm 3.2$ & $135.9 \pm 4.4$ \\
\hline $2.0 \mathrm{mg} \cdot \mathrm{kg}^{-1} \cdot \mathrm{day}^{-1}$ & 14 & $474 \pm 10$ & $346 \pm 11$ & $56.5 \pm 3.7$ & $127.4 \pm 3.9$ \\
\hline $4.0 \mathrm{mg} \cdot \mathrm{kg}^{-1} \cdot \mathrm{day}^{-1}$ & 14 & $483 \pm 11$ & $340 \pm 17$ & $56.8 \pm 2.8$ & $114.9 \pm 4.2$ \\
\hline $8.0 \mathrm{mg} \cdot \mathrm{kg}^{-1} \cdot \mathrm{day}^{-1}$ & 13 & $496 \pm 14$ & $348 \pm 13$ & $56.4 \pm 2.9$ & $125.8 \pm 4.6$ \\
\hline
\end{tabular}

Data are mean $\pm \mathrm{SEM}$

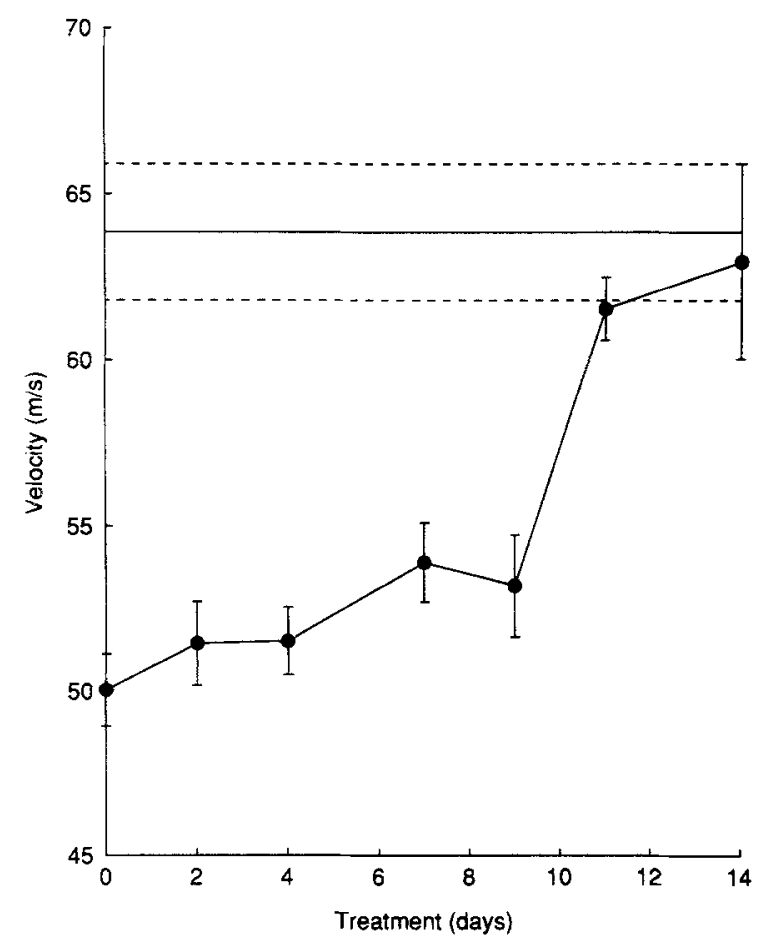

Fig.2. Estimation of the timecourse of recovery of sciatic conduction velocity by ZD5522 treatment after 4 months of untreated diabetes $(n=7)$ using serial measurements for the motor fibres to tibialis anterior muscle. Data are means \pm SEM. Horizontal solid line flanked by dashed lines indicates mean \pm SEM for a group of non-diabetic rats $(n=10)$. Statistics: compared to baseline (day 0$)$, NCV was improved on days $7(p<0.05), 11$ and $14(p<0.0001)$

values consistently obtained from our model. The reason for this is not clear but it may relate to blood samples being taken at the end of experiments rather than at the start, greater time being available for glycogen mobilisation during the course of the experiments. Body weights and mean systemic arterial blood pressures recorded during sciatic blood flow measurements are also given in Table 2. Diabetes caused a fall in body weight that was not significantly affected by ZD5522 treatment. One-way analysis of variance showed that there was a significant variation in blood pressure $(p=0.029)$; however, post hoc Bonferroni analysis could not assign this to a particular between-group comparison, although there was a $16 \%$ numerical difference between lowest (diabetic control) and highest $\left(1.0 \mathrm{mg} \cdot \mathrm{kg}^{-1}\right.$ treatment) group mean values.

Sciatic nerve glucose, sorbitol, fructose and myo-inositol concentrations are shown in Table 3. Diabetes caused an approximately five-fold increase in glucose which was unaffected by ZD5522 treatment. Sorbitol and fructose concentrations were 13.8 -fold and 6.9 -fold elevated by diabetes. There were dose-dependent reductions in the levels of sciatic sorbitol and fructose. Differential effects on these metabolites are revealed by the $\mathrm{ED}_{50}$ levels for $\mathrm{ZD} 5522$. Log $\mathrm{ED}_{50}$ values, as a measure of sensitivity to treatment, are given in Table 4. Sorbitol accumulation was more sensitive than fructose to ZD5522 by a factor of 3.2. There was an approximately $40 \%$ reduction in nerve myo-inositol concentration, which was partially normalized by treatment. The small size of between-group differences and variability precluded accurate estimation of myo-inositol $\log \mathrm{ED}_{50}$, but this must have been below 0 $\left(1.0 \mathrm{mg} \cdot \mathrm{kg}^{-1}\right)$, probably around $-0.3\left(0.5 \mathrm{mg} \cdot \mathrm{kg}^{-1}\right)$. Saphenous nerve showed a rather different pattern of polyol accumulation. Sorbitol levels in untreated diabetes were approximately one tenth of those in sciatic nerve, however, there was a dose-dependent reduction with ZD5522 treatment. Fructose concentration was also elevated by diabetes, but was only slightly affected by ZD5522 treatment. Saphenous myo-inositol content decreased by $36 \%$ with diabetes.

The dose-response curve for sciatic motor NCV is shown in Figure $3 \mathrm{~A}$. At the highest ZD5522 dose employed $\left(8 \mathrm{mg} \cdot \mathrm{kg}^{-1}\right)$, NCV was marginally lower than for non-diabetic controls $(p \leq 0.05$ ), however, it was significantly lower for reduced doses. The $\mathrm{L} o g \mathrm{ED}_{50}$ for motor NCV (Table 4) was approximately $1 \log$ unit greater than for the biochemical measures of sorbitol 
Table 3. Sciatic nerve glucose and sciatic and saphenous nerve sorbitol, fructose and myo-inositol concentrations (nmol $\cdot$ mg wet weight $^{-1}$ )

\begin{tabular}{|c|c|c|c|c|c|c|c|c|}
\hline \multirow[b]{2}{*}{ Group } & \multirow[b]{2}{*}{$n$} & \multirow[b]{2}{*}{ Glucose } & \multicolumn{3}{|l|}{ Sciatic nerve } & \multicolumn{3}{|l|}{ Saphenous nerve } \\
\hline & & & Sorbitol & Fructose & myo-inositol & Sorbitol & Fructose & myo-inositol \\
\hline Control & 12 & $3.24 \pm 0.33$ & $0.229 \pm 0.015$ & $1.22 \pm 0.05$ & $2.96 \pm 0.12$ & $0.109 \pm 0.007$ & $0.55 \pm 0.06$ & $1.71 \pm 0.14$ \\
\hline \multicolumn{9}{|l|}{ Diabetic } \\
\hline Untreated & 11 & $16.24 \pm 1.42^{c}$ & $3.149 \pm 0.230^{c}$ & $8.47 \pm 0.73^{c}$ & $1.79 \pm 0.11^{c}$ & $0.365 \pm 0.051^{\circ}$ & $1.76 \pm 0.23^{a}$ & $1.07 \pm 0.17^{\mathrm{a}}$ \\
\hline \multicolumn{9}{|c|}{ ZD5522-treated diabetic } \\
\hline $0.25 \mathrm{mg} \cdot \mathrm{kg}^{-1} \cdot \mathrm{day}^{-1}$ & 11 & $15.17 \pm 0.65^{\mathrm{c}}$ & $0.642 \pm 0.028^{\mathrm{b}, \mathrm{g}}$ & $3.82 \pm 0.17^{\mathrm{c}, \mathrm{g}}$ & $1.90 \pm 0.10^{\circ}$ & $0.195 \pm 0.022^{\mathrm{a}, \mathrm{g}}$ & $2.90 \pm 0.31^{c}$ & $1.77 \pm 0.16^{\mathrm{e}}$ \\
\hline $0.50 \mathrm{mg} \cdot \mathrm{kg}^{-1} \cdot \mathrm{day}^{-1}$ & 14 & $16.34 \pm 1.12^{c}$ & $0.437 \pm 0.029^{\mathrm{g}}$ & $3.44 \pm 0.18^{\mathrm{c} g}$ & $2.11 \pm 0.09^{c}$ & $0.144 \pm 0.013^{\mathrm{g}}$ & $3.05 \pm 0.54^{\mathrm{c}}$ & $1.93 \pm 0.27^{\mathrm{e}}$ \\
\hline $1.0 \mathrm{mg} \cdot \mathrm{kg}^{-1} \cdot \mathrm{day}^{-1}$ & 11 & $18.39 \pm 0.98^{c}$ & $0.180 \pm 0.014^{\mathrm{g}}$ & $2.28 \pm 0.15^{\mathrm{a}, \mathrm{g}}$ & $2.45 \pm 0.10^{f}$ & $0.063 \pm 0.007^{\mathrm{g}}$ & $2.44 \pm 0.19^{b}$ & $1.41 \pm 0.11$ \\
\hline $2.0 \mathrm{mg} \cdot \mathrm{kg}^{-1} \cdot \mathrm{day}^{-1}$ & 13 & $17.72 \pm 1.45^{c}$ & $0.100 \pm 0.006^{\mathrm{g}}$ & $1.64 \pm 0.09^{s}$ & $2.21 \pm 0.09^{c}$ & $0.065 \pm 0.006^{8}$ & $2.29 \pm 0.29^{b}$ & $1.54 \pm 0.10$ \\
\hline $4.0 \mathrm{mg} \cdot \mathrm{kg}^{-1} \cdot \mathrm{day}^{-1}$ & 14 & $16.83 \pm 0.75^{\mathfrak{c}}$ & $0.073 \pm 0.010^{\circ}$ & $1.33 \pm 0.11^{q}$ & $2.41 \pm 0.13^{\mathrm{a}, \mathrm{f}}$ & $0.087 \pm 0.008^{8}$ & $2.05 \pm 0.27^{a}$ & $1.64 \pm 0.13$ \\
\hline $8.0 \mathrm{mg} \cdot \mathrm{kg}^{-1} \cdot \mathrm{day}^{-1}$ & 13 & $17.52 \pm 0.75^{\mathrm{c}}$ & $0.060 \pm 0.009^{\mathrm{g}}$ & $1.19 \pm 0.05^{g}$ & $2.51 \pm 0.11^{f}$ & $0.079 \pm 0.006^{\mathrm{g}}$ & $1.87 \pm 0.17^{\mathrm{a}}$ & $1.50 \pm 0.10$ \\
\hline \multicolumn{9}{|c|}{$\begin{array}{ll} & \\
& p<0.05,{ }^{b} p<0.01,{ }^{c} p<0.001 ; \\
\text { diabetic control group } & { }^{\mathrm{e}} p \\
\end{array}$} \\
\hline & & & \multicolumn{2}{|c|}{$\log \mathrm{ED}_{50}$} & \multicolumn{2}{|c|}{ Estimated } & \multicolumn{2}{|c|}{$95 \%$ confidence } \\
\hline & & & \multicolumn{3}{|c|}{$\log _{10}\left(\mathrm{mg} \cdot \mathrm{kg}^{-1} \cdot \mathrm{day}^{-1}\right)$} & EM & limits & \\
\hline \multicolumn{3}{|c|}{ Sciatic motor conduction velocity } & \multicolumn{2}{|c|}{0.128} & \multicolumn{2}{|c|}{0.039} & \multicolumn{2}{|c|}{0.019 to 0.236} \\
\hline \multicolumn{3}{|c|}{ Sciatic sorbitol } & \multicolumn{2}{|c|}{-1.235} & \multicolumn{2}{|c|}{0.088} & \multicolumn{2}{|c|}{-1.469 to -1.002} \\
\hline \multicolumn{3}{|l|}{ Sciatic fructose } & \multicolumn{2}{|c|}{-0.724} & \multicolumn{2}{|c|}{0.079} & \multicolumn{2}{|c|}{-0.943 to -0.505} \\
\hline \multicolumn{3}{|l|}{ Sciatic blood flow } & \multicolumn{2}{|c|}{0.063} & \multicolumn{2}{|c|}{0.085} & \multicolumn{2}{|c|}{-0.173 to 0.299} \\
\hline \multicolumn{3}{|c|}{ Sciatic vascular conductance } & \multicolumn{2}{|c|}{0.238} & \multicolumn{2}{|c|}{0.050} & \multicolumn{2}{|c|}{0.099 to 0.376} \\
\hline \multicolumn{3}{|c|}{ Saphenous sensory conduction velocity } & -0 & 230 & & .023 & -0.294 to & -0.165 \\
\hline Saphenous sorbitol & & & -0 & 712 & & 290 & -1.517 to & 0.093 \\
\hline
\end{tabular}

and fructose. Similar data for saphenous nerve (Fig. 3B) showed complete reversal of the NCV deficit at the highest ARI dose. Saphenous sensory Log ED $D_{50}$ (Table 4) was approximately $0.3 \mathrm{log}$ units lower than that for sciatic motor NCV and the $95 \%$ confidence limits for the two measures do not overlap, indicating a greater sensitivity of saphenous nerve to ZD5522 treatment.

Results for laser-Doppler estimates of whole sciatic nerve blood flow and vascular conductance are shown in Figure 4. Flow was $59.9 \%$ reduced by untreated diabetes and was increased in a dose-dependent fashion such that the values obtained for ZD5522 doses greater than $0.25 \mathrm{mg} \cdot \mathrm{kg}^{-1}$ were significantly improved compared to untreated diabetes $(p<0.05)$ and, at 4.0 and $8.0 \mathrm{mg} \cdot \mathrm{kg}^{-1}$ doses, flow was not significantly different from non-diabetic control rats (Fig. 4 A). Vascular conductance showed a $43.6 \%$ deficit with untreated diabetes (Fig. 4B). This was significantly improved by treatment at doses $1.0 \mathrm{mg} \cdot \mathrm{kg}^{-1}$ or greater $(p<0.05)$; the two highest doses not being significantly different from control values. The $\log \mathrm{ED}_{50}$ values for laser-
Doppler flow and conductance improvements were similar to those for functional effects on sciatic motor NCV (Table 4). There was a strong correlation between motor NCV and blood flow when data from all diabetic groups were pooled $(r=0.765, p<0.0001)$. The best correlation was found when between-rat and between-group variations in blood pressure were taken into account using motor NCV as the dependent variable and vascular conductance as the independent variable (Fig. 5).

\section{Investigation 4: sciatic endoneurial blood flow and oxygen tensions measured by microelectrode polarography}

The laser-Doppler method of measuring blood flow can be rather inaccurate, does not discriminate between nutritive (capillary) and non-nutritive (larger vessel and anastomotic) flow or endoneurial from epi/perineurial flow, and is insensitive to changes in flow patterns $[22,23]$. Therefore, to further investigate 

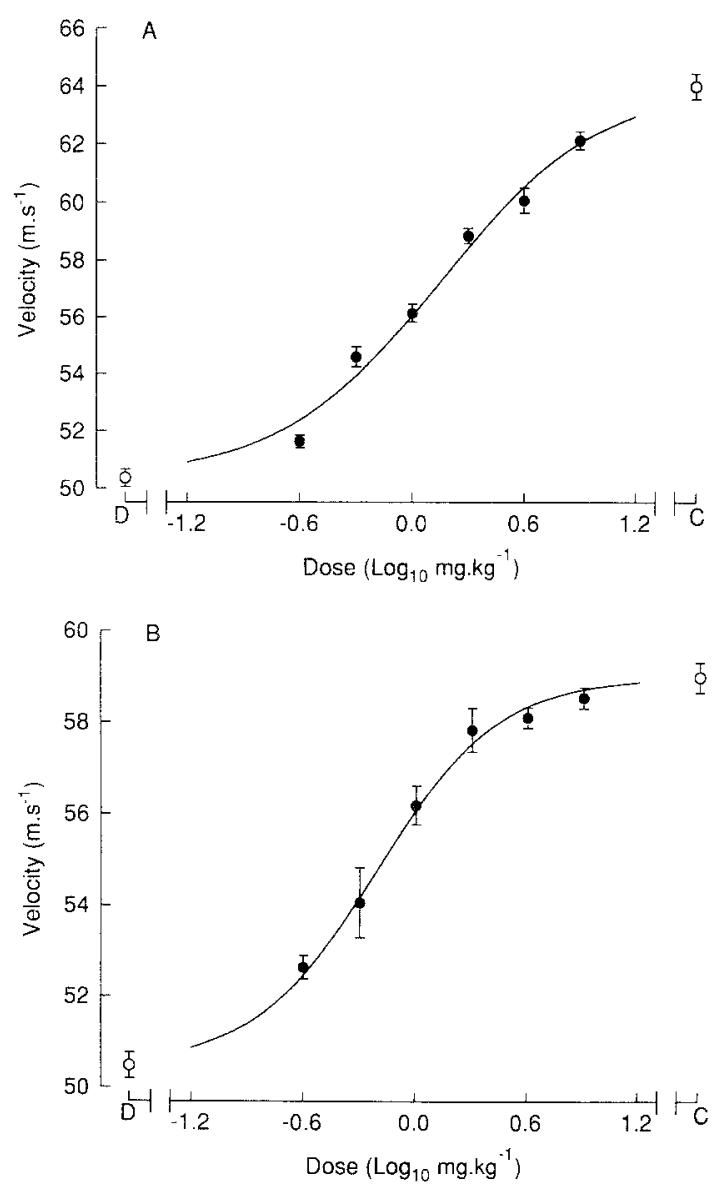

Fig.3A ana B. Dose-response curves for sciatic motor (A) and saphenous sensory (B) conduction velocity recovery with 1 month ZD5522 treatment following 2 months untreated diabetes. Treatment was given at doses of $0.25, n=11$; $0.5, n=14 ; 1.0, n=11 ; 2.0, n=14 ; 4.0, n=14 ;$ and $8.0, n=13$, $\mathrm{mg} \cdot \mathrm{kg}^{-1} \cdot \mathrm{day}^{-1} . \mathrm{D}$, untreated diabetic group, $n=11 ; \mathrm{C}$, nondiabetic control group, $n=12$. Data are means \pm SEM. Statistics - motor NCV: control vs untreated diabetes and $0.25-4.0 \mathrm{mg} \cdot \mathrm{kg}^{-1} \cdot \mathrm{day}^{-1}, p<0.001,8.0 \mathrm{mg} \cdot \mathrm{kg}^{-1} \cdot \mathrm{day}^{-1}, p \leq 0.05$; untreated diabetic vs $0.5-8.0 \mathrm{mg} \cdot \mathrm{kg}^{-1} \cdot \mathrm{day}^{-1}, p<0.001$. Sensory NCV: control vs untreated diabetic, 0.25 and $0.5 \mathrm{mg}$. $\mathrm{kg}^{-1} \cdot$ day $^{-1}, \quad p<0.001,1.0 \mathrm{mg} \cdot \mathrm{kg}^{-1} \cdot$ day $^{-1}, p<0.01$; untreated diabetic vs $0.25 \mathrm{mg} \cdot \mathrm{kg}^{-1} \cdot \mathrm{day}^{-1}, p<0.05,0.5-8.0 \mathrm{mg} \cdot \mathrm{kg}^{-1} \cdot \mathrm{day}^{-1}$, $p<0.001$

whether ARI treatment affected nutritive endoneurial perfusion, hydrogen clearance from the endoneurium was monitored by microelectrode polarography. Endoneurial oxygen tensions were also measured in separate groups of rats using oxygen-sensitive microelectrodes. Duration of diabetes was 2 months and ZD5522 treatment $\left(8 \mathrm{mg} \cdot \mathrm{kg}^{-1} \cdot \mathrm{day}^{-1}\right)$ was given from induction. Body weights and plasma glucose values are given in Table 5, and these showed the typical weight loss and hyperglycaemia with diabetes that was unaffected by treatment.

Endoneurial nutritive blood flow (Fig. 6A) was $45 \%$ reduced by untreated diabetes $(p<0.001)$ and this was completely prevented by ZD5522 treatment ( $p<$ 0.001 ). ZD5522 treatment for a group of non-diabetic
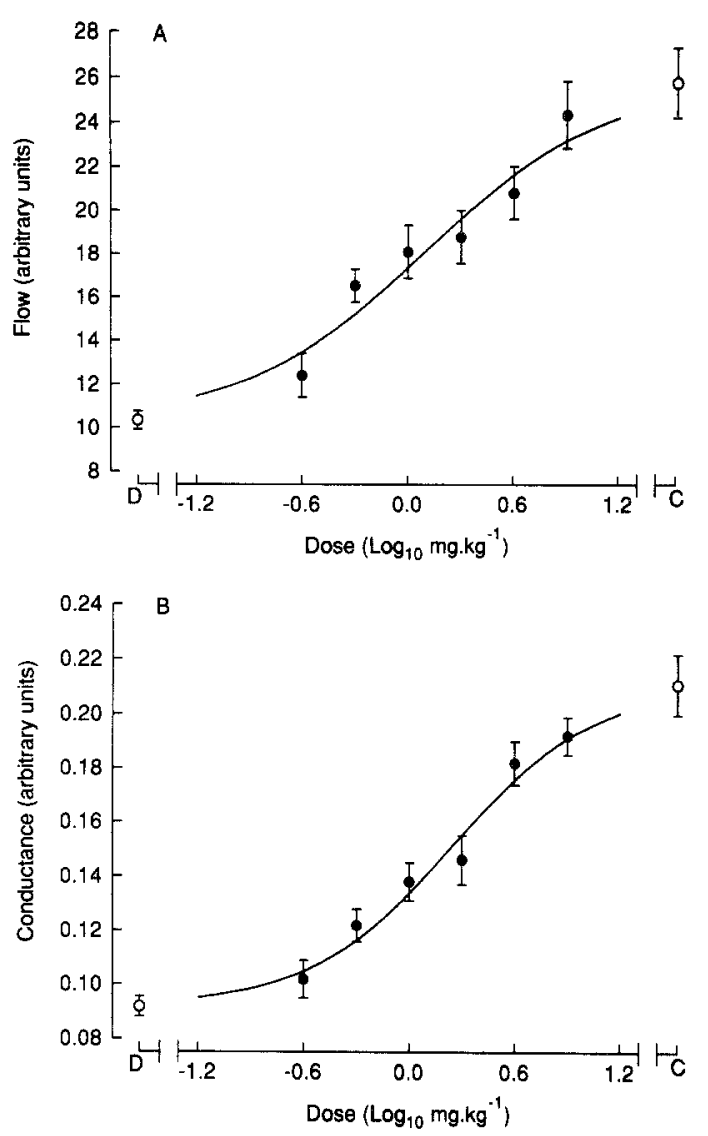

Fig.4A and B. Dose-response curves for laser-Doppler estimates of sciatic nerve blood flow (A) and vascular conductance (B) for diabetic rats given ZD5522 treatment for 1 month following 2 months untreated diabetes. Treatment was given at doses of $0.25, n=11 ; 0.5, n=14 ; 1.0, n=11 ; 2.0, n=14 ; 4.0, n=14$; and $8.0, n=13, \mathrm{mg} \cdot \mathrm{kg}^{-1} \cdot$ day $^{-1} . \mathrm{D}$, untreated diabetic group, $n=11$; $\mathrm{C}$, non-diabetic control group, $n=12$. Data are means \pm SEM. Statistics - flow: control vs untreated diabetic, 0.25 and $0.5 \mathrm{mg} \cdot \mathrm{kg}^{-1} \cdot \mathrm{day}^{-1}, p<0.001,1.0$ and $2.0 \mathrm{mg} \cdot \mathrm{kg}^{-1} \cdot \mathrm{day}^{-1}, p<0.01$; untreated diabetic vs $0.5 \mathrm{mg} \cdot \mathrm{kg}^{-1} \cdot \mathrm{day}^{-1}, p<0.05,1.0 \mathrm{mg} \cdot \mathrm{kg}^{-1}$. day $^{-1}, p<0.01,2.0-8.0 \mathrm{mg} \cdot \mathrm{kg}^{-1} \cdot \mathrm{day}^{-1}, p<0.001$. Conductance: control vs untreated diabetic and $0.25-2.0 \mathrm{mg} \cdot \mathrm{kg}^{-1} \cdot$ day $^{-1}$, $p<0.001$; untreated diabetic vs $1.0 \mathrm{mg} \cdot \mathrm{kg}^{-1} \cdot \mathrm{day}^{-1}, p<0.05$, $2.0 \mathrm{mg} \cdot \mathrm{kg}^{-1} \cdot \mathrm{day}^{-1}, p<0.01,4.0$ and $8.0 \mathrm{mg} \cdot \mathrm{kg}^{-1} \cdot \mathrm{day}^{-1}, p<0.001$

rats did not cause any significant effects on blood flow. One-way analysis of variance showed a significant $(p=0.03)$ variation in systemic blood pressure (Table 5). Post hoc Bonferroni analysis showed that the main difference was found between ZD5522-treated diabetic and ZD5522-treated control groups $(p<0.05)$. When pressure differences were compensated for by expressing the data in terms of endoneurial vascular conductance (Fig. $6 \mathrm{~B}$ ), there was a $44 \%$ reduction for untreated diabetes $(p<0.001)$, and complete prevention with ZD5522 treatment $(p<0.001)$.

In contrast to ZD5522, preventive myo-inositol treatment of diabetic rats had no significant effect on endoneurial nutritive blood flow or vascular conductance (Figs.6 $\mathrm{A}$ and $6 \mathrm{~B}$ ), both of which remained re- 
Table 5. Body weights, plasma glucose concentrations and blood pressure in non-diabetic, diabetic, ZD5522-treated and myo-inositol-treated diabetic rats used for nutritive endoneurial blood flow measurements

\begin{tabular}{lllll}
\hline Group & $n$ & $\begin{array}{l}\text { Body weight } \\
(\mathrm{g})\end{array}$ & $\begin{array}{l}\text { Plasma glucose } \\
\left(\mathrm{mmol} \cdot \mathrm{l}^{-1}\right)\end{array}$ & $\begin{array}{l}\text { Blood pressure } \\
(\mathrm{mm} \mathrm{Hg})\end{array}$ \\
\hline Control & 8 & $500 \pm 10$ & $6.8 \pm 0.3$ & $129.2 \pm 5.5$ \\
2-month ZD5522-treated control & 8 & $542 \pm 15$ & $7.6 \pm 0.6$ & $139.2 \pm 5.2$ \\
2-month diabetic & 8 & $384 \pm 8^{\mathrm{a}}$ & $36.4 \pm 3.7^{\mathrm{a}}$ & $123.6 \pm 5.8$ \\
2-month ZD5522-treated diabetic & 8 & $352 \pm 11^{\mathrm{a}}$ & $41.1 \pm 2.3^{\mathrm{a}}$ & $116.8 \pm 3.7$ \\
2-month myo-inositol-treated diabetic & 10 & $346 \pm 12^{\mathrm{a}}$ & $41.7 \pm 3.2^{\mathrm{a}}$ & $116.6 \pm 4.1$ \\
\hline
\end{tabular}

${ }^{a} p<0.001$ compared to control group

Data are mean \pm SEM

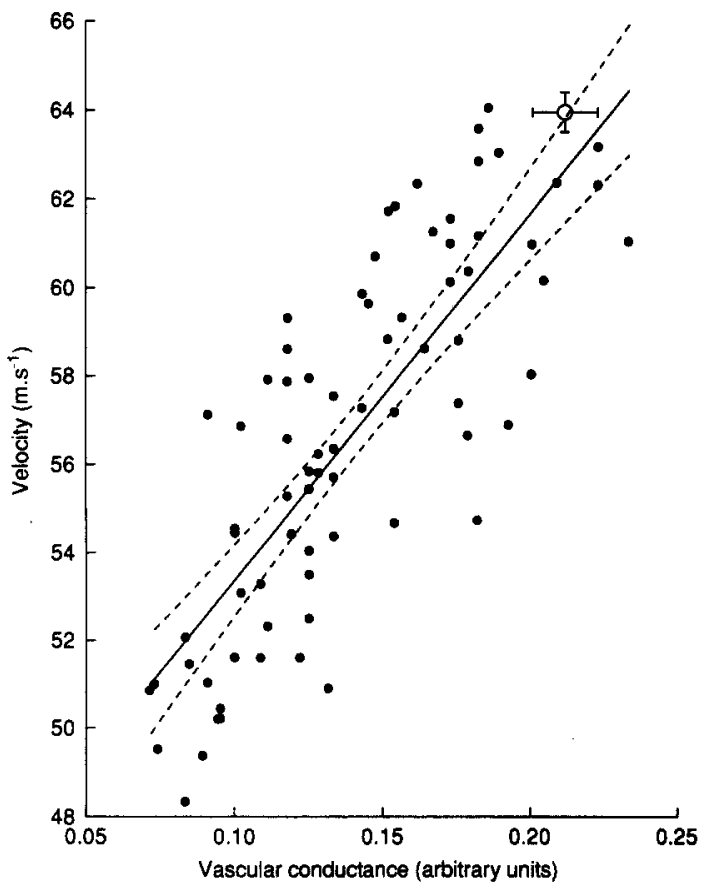

Fig. 5. Regression and correlation between sciatic vascular conductance and motor conduction velocity for diabetic and ZD5522-treated diabetic rats. Data points from untreated diabetic and $0.25-8.0 \mathrm{mg} \cdot \mathrm{kg}^{-1} \cdot$ day $^{-1} \mathrm{ZD} 5522$-treated diabetic groups ( ). Mean for the non-diabetic control group (O) \pm SEM. Solid line, best fitting linear regression $(r=0.81$, $p<0.0001$ ), and $95 \%$ confidence limits (dashed lines)

duced compared to controls $(p<0.001)$. The myo-inositol treatment elevated plasma levels from around $0.030 \pm 0.004 \mathrm{mmol} \cdot \mathrm{l}^{-1}$ found in control $(n=10)$ and $0.036 \pm 0.004 \mathrm{mmol} \cdot \mathrm{l}^{-1}$ in 2 -month diabetic rats $(n=$ $10)$ to $0.422 \pm 0.068 \mathrm{mmol} \cdot 1^{-1}(n=10, p<0.001)$. Sciatic nerve myo-inositol was also elevated to $2.20 \pm$ $0.07 \mathrm{nmol} \cdot \mathrm{mg}$ wet weight ${ }^{-1}$, a value greater $(p<0.001)$ than found with 2-month untreated diabetes $(1.14 \pm$ $0.08 \mathrm{nmol} \cdot \mathrm{mg}$ wet weight ${ }^{-1}$ ) and that matched or exceeded values in samples from non-diabetic rats $\left(2.02 \pm 0.17 \mathrm{nmol} \cdot \mathrm{mg}\right.$ wet weight $\left.{ }^{-1}\right)$ measured at the same time. Motor NCV in the tibialis anterior branch of the sciatic nerve was unaffected by myo-inositol treatment, being $49.9 \pm 1.2 \mathrm{~m} \cdot \mathrm{s}^{-1}$, which is not significantly different from that found for 2-month untreated diabetes $\left(50.4 \pm 0.7 \mathrm{~m} \cdot \mathrm{s}^{-1}\right.$, for the tibialis anterior com-

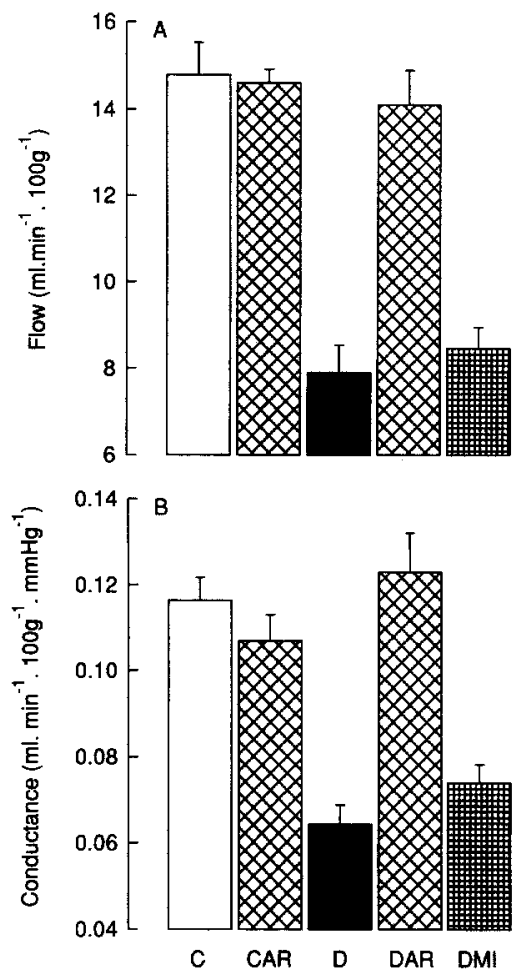

Fig.6 $\mathrm{A}$ and B. Nutritive endoneurial blood flow (A) and vascular conductance (B) measured by hydrogen clearance in nondiabetic and diabetic rats with and without 2 months ZD5522 treatment and for myo-inositol-treated diabetic rats. C, control group, $n=8$; CAR, control rats treated with ZD5522 for 2 months $\left(8.0 \mathrm{mg} \cdot \mathrm{kg}^{-1} \cdot \mathrm{day}^{-1}\right), n=8 ; \mathrm{D}, 2$-month untreated diabetic group, $n=8$; DAR, 2-month ZD5522-treated diabetic group, $n=8$; DMI, 2-month myo-inositol-treated diabetic group, $n=10$. Data are means \pm SEM. Statistics for both flow and conductance: C vs D or DMI, $p<0.001$; C vs CAR or DAR, $\mathrm{NS}$; D vs DAR, $p<0.001 ; \mathrm{D}$ vs DMI, NS

ponent of motor NCV from investigation 1), but was $21.7 \%$ reduced compared to non-diabetic control values $\left(63.7 \pm 0.7 \mathrm{~m} \cdot \mathrm{s}^{-1}, p<0.001\right)$.

The effect of a structurally unrelated ARI, ponalrestat, on endoneurial blood flow was also determined in a preventive experiment over a 1 month period of diabetes. Results are given in Table 6. One month diabetes caused a $43.6 \%$ decrease in blood flow. Systemic blood pressure tended to be lower in diabetic groups than controls. When this was taken into ac- 
Table 6. Effects of diabetes and ponalrestat treatment on sciatic nerve nutritive endoneurial blood flow

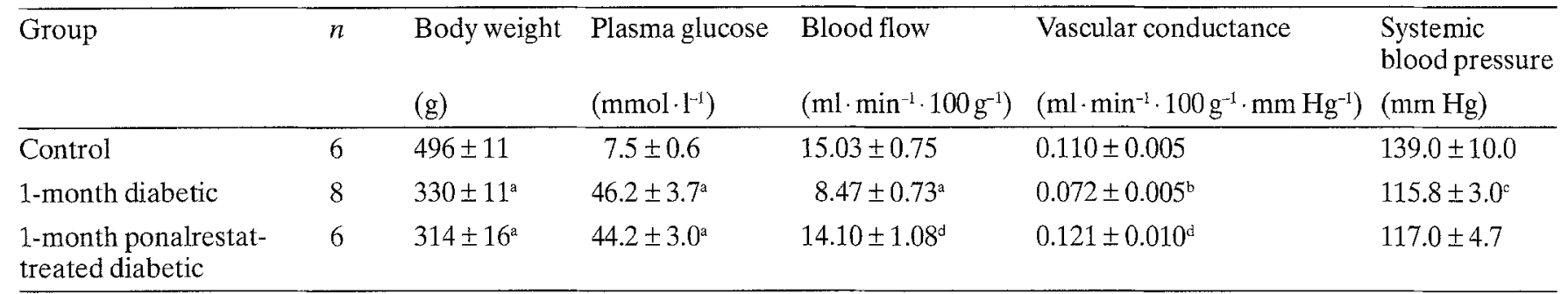

${ }^{\mathrm{a}} p<0.001,{ }^{\mathrm{b}} p<0.01,{ }^{c} p<0.05$ compared to control group;

Data are mean \pm SEM

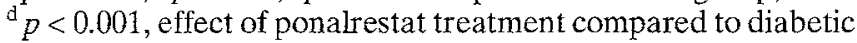
group

Table 7. Estimates of non-nutritive endoneurial blood flow in pooled data from groups in the ZD5522 and ponalrestat experiments

\begin{tabular}{lrlll}
\hline Group & $n$ & $\begin{array}{l}\text { Relative nutritive flow } \\
(\%)\end{array}$ & $\begin{array}{l}\text { Fast component flow } \\
\left(\mathrm{ml} \cdot \mathrm{min}^{-1} \cdot 100 \mathrm{~g}^{-1}\right)\end{array}$ & $\begin{array}{l}\text { Fast component conductance } \\
\left(\mathrm{ml} \cdot \mathrm{min}^{-1} \cdot 100 \mathrm{~g}^{-1} \mathrm{~mm} \mathrm{Hg}^{-1}\right)\end{array}$ \\
\hline Control & 14 & $54.9 \pm 4.7$ & $99.6 \pm 13.3$ & $0.705 \pm 0.083$ \\
ARI-treated control & 8 & $53.0 \pm 4.7$ & $88.8 \pm 4.3$ & $0.646 \pm 0.043$ \\
Diabetic (1 and 2 months) & 16 & $58.9 \pm 5.6$ & $51.4 \pm 4.0^{\mathrm{a}}$ & $0.455 \pm 0.032^{\mathrm{c}}$ \\
ARI-treated diabetic & 14 & $84.0 \pm 4.9^{\mathrm{b}, \mathrm{f}}$ & $82.8 \pm 9.1(8)^{\mathrm{e}, \mathrm{g}}$ & $0.684 \pm 0.089(8)^{\mathrm{e}, \mathrm{f}}$ \\
myo-inositol treated diabetic & 10 & $47.6 \pm 4.1$ & $41.7 \pm 6.0^{\mathrm{a}}$ & $0.345 \pm 0.059^{\mathrm{b}}$ \\
\hline
\end{tabular}

${ }^{\mathrm{a}} p<0.001,{ }^{\mathrm{b}} p<0.01,{ }^{\mathrm{c}} p<0.05$ compared to control rats;

d $p<0.01,{ }^{\mathrm{e}} p<0.05$ effect of ARI treatment compared to diabetic rats;

${ }^{\mathrm{f}} p<0.01,{ }^{\mathrm{g}} p<0.05$ effect of ARI treatment compared to myo-inositol-treated diabetic rats.

Table 8. Body weights, plasma glucose concentrations, mean systemic blood pressures and arterial oxygen tensions in non-diabetic, diabetic and ZD5522-treated diabetic rats used for endoneurial oxygen tension measurements

\begin{tabular}{lllll}
\hline Group & $n$ & $\begin{array}{l}\text { Body weight } \\
(\mathrm{g})\end{array}$ & $\begin{array}{l}\text { Plasma glucose } \\
\left(\mathrm{mmol} \cdot \mathrm{l}^{-1}\right)\end{array}$ & $\begin{array}{l}\text { Blood pressure } \\
(\mathrm{mm} \mathrm{Hg})\end{array}$ \\
\hline Control & 8 & $507 \pm 8$ & $10.2 \pm 0.8$ & $140.1 \pm 10.1$ \\
2-month diabetic & 8 & $336 \pm 9^{\mathrm{a}}$ & $37.2 \pm 3.1^{\mathrm{a}}$ & $99.3 \pm 3.5$ \\
ZD5522-treated diabetic & 8 & $339 \pm 8^{\mathrm{a}}$ & $38.2 \pm 1.7^{\mathrm{a}}$ & $97.7 \pm 2.8$ \\
\hline
\end{tabular}

${ }^{a} p<0.001$ compared to control group

Data are mean \pm SEM. $\mathrm{PaO}_{2}$, Arterial oxygen tension

count, there was a $34.5 \%$ deficit in vascular conductance. Ponalrestat treatment completely prevented both changes; the values obtained were not significantly different from those for the non-diabetic control group.

Hydrogen clearance curves for blood flow measurements generally contain two components. One, with a fast exponent, is derived from flow in large vessels. The second, slower component results from nutritive capillary flow [22]. The relative contribution of the nutritive component to the composite curve was $54.9 \pm 4.7 \%$ for non-diabetic control rats used in the ZD5522 and ponalrestat studies. This was not affected by diabetes or by ZD5522 treatment of non-diabetic rats. However, ARI-treatment of diabetic rats changed the pattern of endoneurial flow in favour of the nutritive supply for
Data are mean \pm SEM. Values in parentheses are group $n$ for a particular measurement where they differ from the number of rats in the group 


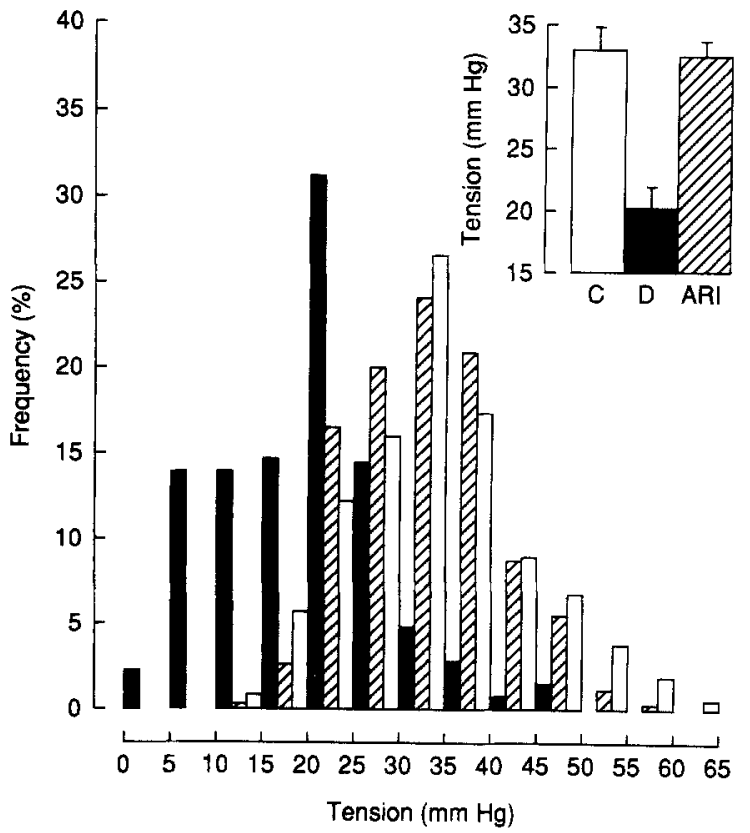

Fig.7. Endoneurial oxygen tension distributions in nondiabetic, diabetic and ZD5522-treated diabetic rats. Oxygen tension histograms ( $5 \mathrm{~mm} \mathrm{Hg}$ bin size) for non-diabetic control (open columns), $n=8$; 2 -month diabetic (solid columns), $n=8$; and 2-month ZD5522-treated $\left(8.0 \mathrm{mg} \cdot \mathrm{kg}^{-1} \cdot \mathrm{day}^{-1}\right.$, hatched columns), $n=8$, groups. Inset histogram, mean \pm SEM endoneurial oxygen tensions. C, non-diabetic control group; D, 2-month diabetic group; ARI, 2-month ZD5522-treated diabetic group. Statistics: C vs D, $p<0.001$; C vs ARI, NS: D vs ARI, $p<0.001$

groups. A similar pattern of effects was noted for vascular conductance of the fast component.

Data for body weights and plasma glucose concentrations for the groups used to determine endoneurial oxygen tensions are given in Table 8 , along with mean systemic arterial blood pressures and arterial oxygen tensions. Endoneurial oxygen tension histograms are shown in Figure 7, and mean values are plotted in the inset graph. There was a characteristic shift towards lower tensions with untreated diabetes which averaged $36.9 \%(p<0.001)$ and was completely prevented by ZD5522 treatment $(p<0.001)$. Only $23.8 \pm 5.9 \%$ of oxygen tension measurements were over $25 \mathrm{~mm} \mathrm{Hg}$ in the diabetic group, which was significantly reduced compared to the control group $(78.0 \pm 7.7 \%, p<0.01)$ or the ZD5522-treated diabetic group $(82.1 \pm 4.4 \%$, $p<0.001$ ).

\section{Discussion}

The data demonstrate that aldose reductase inhibition with ZD5522 corrects the NCV deficits found in experimental diabetes, in common with several other structurally unrelated ARIs [1-3]. Using a high-level polyol pathway blockade, NCV restoration was rapid even after 4 months of diabetes. Rapid NCV reversal also occurs for diverse treatments including electrical
N.E. Cameron et al.: Aldose reductase inhibition and nerve perfusion

stimulation, evening primrose oil and vasodilators, which improve nerve vascular supply without affecting polyol levels $[2,14,19,24]$.

Dose-response curves show that correction of NCV deficits requires a high degree of polyol pathway inhibition. Thus, $10 \%$ amelioration of sciatic motor NCV corresponds to approximately $69 \%$ and $46 \%$ inhibitions of nerve sorbitol and fructose accumulation. Similarly, $90 \%$ NCV correction requires $99 \%$ suppression of sorbitol and $90 \%$ inhibition of fructose; a very high level of blockade, to the point of complete normalization. This could explain the discrepancy between the marked ARI effects in experimental diabetes and the very modest action of low ARI doses in clinical trials [5, 7,8].

Polyol pathway metabolites were much lower in saphenous than sciatic nerve and the response to ZD5522 treatment differed. Both showed reductions in sorbitol levels, however, saphenous fructose showed no clear dose-dependency. The reason is uncertain but could indicate non-polyol pathway fructose production. Myoinositol was reduced by diabetes in both nerves, with partial correction for sciatic and complete correction for saphenous nerve at the lowest ZD5522 dose, which had little effect on NCV. Thus, myo-inositol changes are not predictive of ARI effects on nerve function.

Lack of a myo-inositol effect on NCV in our model agrees with a previous investigation [3] and with longterm experiments for other models employing mature animals [25]. By contrast, in short-term experiments on younger rats, myo-inositol prevents NCV deficits $[1,9]$. The reason for this discrepancy is unclear but myo-inositol effects may be shortlived or only apparent for growing rather than mature nerve fibres. Endoneurial blood flow data paralleled those for NCV. Acute experiments on rabbit aorta in vitro showed that myoinositol prevents hyperglycaemia-induced deficits in smooth muscle $\mathrm{Na}^{+}-\mathrm{K}^{+}$-ATPase activity and endothelium-dependent relaxation to acetylcholine [16]. The data suggest the mechanisms responsible for these acute myo-inositol-dependent deficits are unlikely to be important for chronic vasa nervorum dysfunction in rats. In marked contrast to myo-inositol, ARIs corrected both NCV and blood flow. Thus, the primary functional action of ARIs on nerve is vascular, and it is not necessary to postulate a mechanistic coupling to impaired myo-inositol metabolism.

The finding of neurovascular ARI effects could explain the low correspondence between the biochemical indicators and nerve function, shown by the very large discrepancy between $\mathrm{ED}_{50}$ values. Thus, nerve sorbitol and fructose reflect axon and Schwann cell polyol pathway activity whereas activity in the endothelium and smooth muscle of vessels controlling nerve blood flow is likely to have much greater functional significance. It is plausible that relative efficacy of ARIs may be different for neuronal and vascular tissues [15]. There was a close relationship between sciatic NCV and laser-Dop- 
pler blood flow, evidenced by the similarity of $\mathrm{ED}_{50}$ values and the strong correlation between NCV and vascular conductance. Further blood flow investigations used microelectrode polarography, the only method that directly measures the nutritive component [22]. They clearly show reduced flow with 1 and 2 month diabetes, in agreement with a previous study [19]. This is the first report of prevention of a nutritive deficit by ARI treatment. The agreement for two structurally unrelated inhibitors suggests that vascular actions were not due to drug-specific non-polyol pathway effects. ARI-dependent changes in the relative contribution of nutritive and non-nutritive hydrogen clearance components in diabetic rats could suggest reduced arterio-venous shunting, thus, diverting blood to nutritive perfusion. These observations are consistent with the effects of manipulation of arterio-venous shunts in non-diabetic rats [22]. The nature of ARI-mediated endoneurial flow changes would tend to minimise detection by laser-Doppler flowmetry, thus, flow increases with that technique were probably largely derived from the epi/perineurial compartment.

The regression between laser-Doppler derived vascular conductance and NCV suggests that the safety factor before chronically impaired perfusion affects sciatic NCV is relatively small, although changes in flow pattern could provide a greater margin. Some RHCF can develop in nerves of diabetic rats even for preventive treatments that produce near-normal NCV [26]. Both RHCF and reduced NCV could reflect adaptive mechanisms to decrease aerobic energy requirements, involving increased reliance on anaerobic metabolism and a reduced trans-membrane $\mathrm{Na}^{+}$gradient with less energy demand by $\mathrm{Na}^{+}-\mathrm{K}^{+}$-ATPase [27]. This is not diabetes-specific; similar mechanisms appear to operate in chronic hypoxaemia and ageing, causing reduced NCV and increased RHCF [22, 28]. These changes can occur in the absence of gross pathology, although reduced perfusion would increase the likelihood of fibre damage by free radicals [29]. Gross degeneration may be limited by the ability to increase RHCF and reduce NCV, only occurring if nerves fall from this adaptive homeostatic plateau into pathophysiology.

Nerve blood flow studies in diabetes are controversial in the sense that they appear to yield different conclusions with different techniques and in different hands. Most hydrogen clearance studies show a deficit with diabetes $[12,13,19,30-33]$. One report of no diabetes-induced effect on sciatic endoneurial flow paralleled a lack of effect on sciatic NCV [34], which is consistent with predictions on the vascular hypothesis. Reduced whole nerve flow has also been demonstrated for laser-Doppler [35-38] and butanol accumulation techniques [39]. In contrast, Tilton et al. [40] and Williamson et al. [41] report enhanced microsphere entrapment by vasa nervorum from diabetic rats which was interpreted as indicating increased blood flow. This interpretation assumes that the properties of vasa nervorum in diabetic and non-diabetic rats are comparable, the only variable being flow [42]. However, there are several reports of changes in microvessel dimensions, encroachment of lumen by endothelial cell hyperplasia, and increased adherence to vessel walls in diabetes [43-45]. These would promote microsphere capture, leading to greater overall entrapment despite a real reduction in blood flow. Thus, the balance of the literature supports the contention that nerve blood flow is decreased in experimental diabetes. Further indirect support comes from the findings that conventional and putative vasodilators improve $\mathrm{NCV}$, and that vasodilator blockade reduces NCV in non-diabetic and diabetic rats. These manipulations are accompanied by angiogenesis or regression of the nerve capillary bed [2, $24,37,46-48]$ appropriate for the predicted changes in flow. In diabetic neuropathic patients, direct and indirect measures show reduced blood flow which results in endoneurial hypoxia [21, 49].

This study clearly demonstrates that ARI treatment improves whole nerve and nutritive flow. A previous investigation reported enhanced hydrogen clearance [31]. One laser-Doppler study showed flow improvements [35], in agreement with the present results, although another study reported negative data [38]. ARIs also prevent increased microsphere entrapment consequent to diabetes or acute glucose infusion $[40$, $41,50]$. Thus, most studies support the view that ARI treatment corrects neurovascular dysfunction in diabetic rats.

The apparent controversy over blood flow changes was one reason for measuring endoneurial oxygen tension. In addition, erythrocyte oxygen unloading is reduced in diabetes due to changes in 2,3-diphosphoglycerate and glycated haemoglobin. Increased blood viscosity and reduced erythrocyte deformability could also potentially contribute to endoneurial hypoxia [51]. Therefore, despite flow improvements, endoneurial hypoxia could have been less amenable to ARI treatment. The data show a marked hypoxic shift in the endoneurial oxygen tension distribution with diabetes, in excellent agreement with the original demonstration of this phenomenon [12]. ZD5522 treatment resulted in a near normal endoneurial oxygen tension distribution. Thus, changes in haemoglobin and rheological factors probably only make a minor contribution to endoneurial hypoxia in experimental diabetes.

ZD5522 attenuated the development of further RHCF, although in the short term it was not reversed, in agreement with previous findings for ponalrestat [8]. RHCF in diabetes depends in part on an adaptation to endoneurial hypoxia involving increased reliance on anaerobic metabolism to supply ATP [22]. Therefore, in improving the endoneurial oxygen tension distribution, ARI treatment should also limit the development of hypoxic resistance by removing the main adaptive stimulus. 
The mechanism for ARI-mediated vascular effects is unclear. An endothelium-dependent relaxation deficit in diabetic rat aorta, due to reduced NO synthesis, release, or action, was prevented by sulphonylnitromethane ARI treatment [15]. Similar effects have since been reported for zopolrestat on rabbit aorta [17]. Acute exposure of non-diabetic rabbit aorta to elevated glucose caused an ARI-preventable deficit in NO-mediated relaxation [16]. It depended on increased oxygen free radical activity and was prevented by scavengers $[52,53]$. This mechanism may act at the vasa nervorum as NCV abnormalities are also prevented by anti-oxidant treatment [54].

In conclusion, ARI treatment improves nerve function by increasing nutritive blood flow and endoneurial oxygen tension; effects that do not depend on correction of myo-inositol levels. An extremely high level of polyol pathway blockade is necessary to ameliorate vascular and NCV deficits. It is unlikely that this level of blockade has been attained in clinical trials, therefore, to date they have not provided an adequate test of the applicability of the polyol pathway hypothesis to patients.

Acknowledgements. NEC is supported by a Wellcome Trust Research Leave Fellowship. KCD and EKM are supported by research studentships from Scotia and ZENECA Pharmaceuticals, respectively.

\section{References}

1. Mayer JH, Tomlinson DR (1983) Prevention of defects of axonal transport and nerve conduction velocity by oral administration of myo-inositol or an aldose reductase inhibitor in streptozotocin-diabetic rats. Diabetologia 25: 433-438

2. Cameron NE, Cotter MA (1993) Potential therapeutic approaches to the treatment or prevention of diabetic neuropathy: evidence from experimental studies. Diabetic Med 10: 593-605

3. Cameron NE, Cotter MA, Robertson S (1989) The effect of aldose reductase inhibition on the pattern of nerve conduction deficits in diabetic rats. Q J Exp Physiol 74: 917-926

4. Willars GB, Townsend J, Tomlinson DR, Compton AM, Churchill RD (1988) Studies on peripheral nerve and lens in long-term experimental diabetes: effects of the aldose reductase inhibitor statil. Metabolism 37: 442-449

5. Boulton AJM, Levin S, Comstock J (1990) A multicentre trial of the aldose-reductase inhibitor, tolrestat, in patients with symptomatic diabetic neuropathy. Diabetologia 33: 431-437

6. Sima AAF, Bril V, Nathaniel V et al. (1988) Regeneration and repair of myelinated fibers in sural-nerve biopsy specimens from patients with diabetic neuropathy treated with sorbinil. New Eng J Med 319: 548-555

7. Florkowski CM, Rowe BR, Nightingale S, Harvey TC, Barnett AH (1991) Clinical and neurophysiological studies of aldose reductase inhibitor ponalrestat in chronic symptomatic diabetic peripheral neuropathy. Diabetes 40: 129-133

8. Cameron NE, Cotter MA (1992) Dissociation between biochemical and functional effects of the aldose reductase inhibitor ponalrestat on peripheral nerve in diabetic rats. Br J Pharmacol 107: 939-944
9. Greene DA, Lattimer SA, Sima AAF (1988) Pathogenesis and prevention of diabetic neuropathy. Diab Metab Rev 4: 201-221

10. Lambourne JE, Brown AM, Calcutt N, Tomlinson DR, Willars GB (1988) Adenosine triphosphatase in nerves and ganglia of rats with streptozotocin-induced diabetes or galactosaemia: effects of aldose reductase inhibition. Diabetologia 31: 379-384

11. Sredy J, Flam BR, Sawicki DR (1991) Adenosine triphosphatase activity in sciatic nerve tissue of streptozocin-induced diabetic rats with and without high dietary sucrose: effects of aldose reductase inhibitors. Proc Soc Exp Biol Med 197: 135-142

12. Tuck RR, Schmelzer JD, Low PA (1984) Endoneurial blood flow and oxygen tension in the sciatic nerves of rats with experimental diabetic neuropathy. Brain 107: 935-950

13. Kihara M, Schmelzer JD, Poduslo JF, Curran FF, Nickander KK, Low PA (1991) Aminoguanidine effect on nerve blood flow, vascular permeability, electrophysiology, and oxygen free radicals. Proc Natl Acad Sci USA 88: 6107-6111

14. Cameron NE, Cotter MA, Robertson S, Maxfield EK (1993) Nerve function in experimental diabetes in rats: effects of electrical stimulation. Am J Physiol 264: E161-E166

15. Cameron NE, Cotter MA (1992) Impaired contraction and relaxation in aorta from streptozotocin-diabetic rats: role of polyol pathway activity. Diabetologia 35: 1011-1019

16. Tesfamariam B, Brown ML, Cohen RA (1992) Aldose reductase and myo-inositol in endothelial cell dysfunction caused by elevated glucose. J Pharmacol Exp Therapeut 263: $153-157$

17. Tesfamariam B, Palacino JJ, Weisbrod RM, Cohen RA (1993) Aldose reductase inhibition restores endothelial cell function in diabetic rabbit aorta. J Cardiovasc Pharmacol 21: 205-211

18. Carey F, Mirrlees DJ, Sennitt CM et al. (1994) Biochemical pharmacology in the rat of the novel aldose reductase inhibitor: ZD5522. Br J Pharmacol 111 [Suppl]: 82 P (Abstract)

19. Cameron NE, Cotter MA, Low PA (1991) Nerve blood flow in early experimental diabetes in rats: relation to conduction deficits. Am J Physiol 261: E1-E8

20. Stribling D, Mirrlees DJ, Harrison HE, Earl DCN (1985) Properties of ICI 128,436, a novel aldose reductase inhibitor and its effects on diabetic complications in the rat. Metabolism 34: 336-344

21. Newrick PG, Wilson AJ, Jakubowski J, Boulton AJM, Ward JD (1986) Sural nerve oxygen tension in diabetes. BMJ 293: 1053-1054

22. Low PA, Lagerlund TD, McManis PG (1989) Nerve blood flow and oxygen delivery in normal, diabetic and ischemic neuropathy. Int Rev Neurobiol 31: 355-438

23. Scarphedisson JO, Hårding $\mathrm{H}$, Thorén $\mathrm{P}$ (1988) Repeated measurements of cerebral blood flow in rats. Comparisons between the hydrogen clearance method and laser Doppler flowmetry. Acta Physiol Scand 134: 133-142

24. Cameron NE, Cotter MA, Dines KC, Robertson S, Cox D (1993) The effects of evening primrose oil on peripheral nerve function and capillarization in streptozotocin-diabetic rats: modulation by the cyclo-oxygenase inhibitor flurbiprofen. Br J Pharmacol 109: 972-979

25. Thomas PK, Jeffreys JGR, Sharma AK, Bajada S (1981) Nerve conduction velocity in experimental diabetes in the rat and rabbit. J Neurol Neurosurg Psychiat 44:233-238

26. Robertson S, Cameron NE, Cotter MA (1992) The effect of the calcium antagonist nifedipine on peripheral nerve function in streptozotocin diabetic rats. Diabetologia 35: 11131117 
27. Ritchie JM (1985) A note on the mechanism of resistance to anoxia and ischaemia in pathophysiological mammalian myelinated nerve. J Neurol Neurosurg Psychiat 48:274-277

28. Schmelzer JD, Low PA (1987) Electrophysiological studies on the effect of age on caudal nerve of the rat. Exp Neurol 96: $612-620$

29. Schmelzer JD, Zochodne DW, Low PA (1989) Ischemic and reperfusion injury of rat peripheral nerve. Proc Natl Acad Sci USA 86: 1639-1642

30. Hotta N, Kakuta H, Fukasawa Het al. (1992) Effect of niceritol on streptozocin-induced diabetic neuropathy in rats. Diabetes 41: 587-591

31. Hotta N, Kakuta H, Koh $N$ et al. (1992) Effect of a new potent aldose reductase inhibitor, "TAT" on diabetic neuropathy of rats. Diabetologia 35 [Suppl]: A151 (Abstract)

32. Cotter MA, Dines KC, Cameron NE (1993) Comparison of the effects of evening primrose oil and the putative active triglyceride, di-linolein mono- $\gamma$-linolenate, on sciatic nerve conduction in diabetic rats: dose-response relationship and modulation of endoneurial blood flow. Diabetic Med 10 [Suppl 3]: P67 (Abstract)

33. Cameron NE, Love A, Maxfield EK, Cotter MA (1993) Vasodilator treatment improves sciatic endoneurial microenvironment and prevents the impaired regenerative response following nerve injury in diabetic rats. Diabetic Med 10 [Suppl 3]: A24 (Abstract)

34. Zochodne DW, Ho LT (1992) Normal blood flow but lower oxygen tension in diabetes of young rats: microenvironment and the influence of sympathectomy. Can J Physiol Pharmacol 70: 651-659

35. Yasuda H, Sonobe M, Yamashita $M$ et al. (1989) Effect of prostaglandin $E_{1}$ analogue TFC 612 on diabetic neuropathy in streptozocin-induced diabetic rats: comparison with aldose reductase inhibitor ONO 2235. Diabetes 38: 832-838

36. Stevens EJ, Lockett MJ, Carrington AL, Tomlinson DR (1993) Essential fatty acid treatment prevents nerve ischaemia and associated conduction anomalies in rats with experimental diabetes mellitus. Diabetologia 36:111-117

37. Maxfield EK, Cameron NE, Cotter MA, Dines KC (1993) Angiotensin II receptor blockade improves nerve function, modulates nerve blood flow and stimulates endoneurial angiogenesis in streptozotocin-diabetic rats. Diabetologia 36: 1230-1237

38. Stevens EJ, Carrington AL, Tomlinson DR (1993) Nerve ischaemia in experimental diabetes. Diabetologia 36 [Suppl1]: A57 (Abstract)

39. Monafo WW, Eliasson SG, Shimazaki S, Sugimoto H (1987) Regional blood flow in resting and stimulated sciatic nerve of diabetic rats. Exp Neurol 99; 607-614

40. Tilton RG, Chang K, Pugliese G et al. (1989) Prevention of hemodynamic and vascular albumin filtration changes in diabetic rats by aldose reductase inhibitors. Diabetes 37 : 1258-1270

41. Williamson JR, Chang K, Frangos M et al. (1993) Hyperglycemic pseudohypoxia and diabetic complications. Diabetes 42: 801-813

42. Heymann MA, Payne BD, Hoffman JIE, Rudolph AM (1977) Blood flow measurements with radionuclide-labelled particles. Prog Cardiovasc Dis 20: 55-79

43. Powell H, Knox D, Lee S et al. (1977) Alloxan diabetic neuropathy: electron microscopic studies. Neurology 27: 60-66

44. Bohlen HG, Hankins KD (1982) Early arteriolar and capillary changes in streptozotocin-induced diabetic rats and intraperitoneal hyperglycaemic rats. Diabetologia $22: 344-348$

45. Lash JM, Bohlen HG (1991) Structural and functional origins of supressed acetylcholine vasodilation in diabetic rat intestinal arteries. Circ Res 69: 1259-1268

46. Cotter MA, Dines KC, Cameron NE (1993) Prevention and reversal of motor and sensory peripheral nerve conduction abnormalities in streptoztocin-diabetic rats by the prostacyclin analogue iloprost. Naunyn-Schmiedeberg's Arch Pharmacol 347: 534-540

47. Cameron NE, Cotter MA, Dines KC, Maxfield EK (1993) Pharmacological manipulation of vascular endothelium in non-diabetic and streptozotocin-diabetic rats: effects on nerve conduction, hypoxic resistance and endoneurial capillarization. Diabetologia 36: 516-522

48. Dines KC, Cotter MA, Cameron NE (1993) Contrasting effects of treatment with $\omega-3$ and $\omega-6$ essential fatty acids on peripheral nerve function and capillarization in streptozotocin-diabetic rats. Diabetologia 36: 1132-1138

49. Tesfaye S, Harris N, Jakubowski JJ, Mody C, Wilson RM, Rennie IG, Ward JD (1993) Impaired blood flow and arteriovenous shunting in human diabetic neuropathy: a novel technique of nerve photography and fluorescein angiography. Diabetologia 36: 1266-1274

50. Hasan K, Santiago J, Williamson J (1993) Acute hyperglycaemia-induced increases in regional blood flow are prevented by pyruvate and by tolrestat. Diabetes 42 [Suppl 1]: 189 A (Abstract)

51. Simpson LO (1988) Aitered blood rheology in the pathogenesis of diabetic and other neuropathies. Muscle Nerve 11: $725-744$

52. Langenstroer P, Pieper GM (1992) Regulation of spontaneous EDRF release in diabetic rat aorta by oxygen free radicals. Am J Physiol 263: H257-H265

53. Tesfamariam B, Cohen RA (1992) Free radicals mediate endothelial cell dysfunction caused by elevated glucose. Am J Physiol 263: H321-H326

54. Cameron NE, Cotter MA, Maxfield EK (1993) Anti-oxidant treatment prevents the development of peripheral nerve dysfunction in streptozotocin-diabetic rats. Diabetologia 36 : 299-304 